\title{
Extent of Teachers' Use of Coping Skills Instructions to Enhance Low-Achieving Students' Ability to Manage Cognitive Learning Tasks Difficulties in Secondary Schools in Anambra State, Nigeria
}

\author{
Glad O. Unachukwu PhD \\ Department of Educational Management and Policy, Nnamdi Azikiwe University, Awka \\ gladina2007@yahoo.com \\ Kingsley Chinaza Nwosu \\ Department of Educational Foundations, Nnamdi Azikiwe University, Awka \\ kingsmcjudec@yahoo.co.uk/kc.nwosu@unizik.edu.ng \\ Onyekuru Bruno PhD \\ Faculty of Education, University of Port Harcourt, Port Harcourt
}

Doi:10.5901/ajis.2015.v4n3p59

\begin{abstract}
The study investigated the extent of teachers' use of coping skills instructions to enhance low-achievers' ability to manage cognitive learning tasks difficulties for sustainable universal basic education programme on the premise that coping skills problems are related to teachers having limited expertise in representing the ideas themselves (Allen \& Dlugokinski, 1992). Two hundred Junior Secondary School 11 low achievers made up of 75 male and 125 female low achievers were sampled from 10 secondary schools in Awka South Local Government Area of Anambra State. Low achievers were identified by their teachers. Researchers-developed 20-item questionnaire validated by experts was used to elicit information from the subjects. Three research questions and one null hypothesis guided the study. Research questions were answered using mean and the null hypothesis was tested with analysis of variance (ANOVA) at 0.05 level of significance. Major findings indicated that, teachers to a greater extent instruct low achievers on the three classes of coping strategies. It was also found that significant differences exist on the extent of instructions in the three strategies. Further analysis with the Scheffe test to ascertain the direction of statistic difference, revealed that differences exist among direct action strategy versus emotion-focused coping strategies, and emotion-focused strategies versus seeking-social- support coping strategies. No significant difference was found to exist between direct action coping strategies and seeking-social-support coping strategies. Recommendations were made.
\end{abstract}

Keywords: coping skills, coping skills instruction, low-achievers, learning difficulties.

\section{Introduction}

Universal Basic Education (UBE) programme is Nigeria's response and commitment to its signatory to the Jomtien 1990 and Delhi 1993 Declarations which brought to the fore a world consensus reflecting an expanded vision of basic education with a view to responding to basic learning needs for all (Okoro, 2010; Ogunlaye \&Udeani, 2010). Okoro (2010) noted that by 1990 statistics showed that there were over 100 million out-of-school children and over 900 million adult illiterates in the world. Prior to these Declarations, there had been lots of international calls for eradication of illiteracy, and the colossal number of illiterates and out-of-school children suggests the failure of the preceding declarations.

Among the cardinal objectives of UBE are the promotion of free, Universal Basic Education for every Nigerian child of school age; and drastic reduction of the incidence of drop-out from the formal school system (FRN, 2000). For this to be achieved efforts must be made to sustain the interest of students who struggle with their academic work. The report of the vision 2020 National Technical Working Group on Education Sector of the Federal Government of Nigeria (2009) has it that the expected enrolment figure for JSS is 9.27 million but the actual is 3.27 million leaving 6 million as unenrolled in JSS. However, the completion rate at the JSS is about 34\%. Again, figures show that a high percentage of girls are progressing to JSS than boys (2005: $55 \%$ female, $49 \%$ male). Among the students who are at the risk of dropping out of school are low achievers. Contemporary trends in education point in the direction of the need to focus on meeting 
individual needs as against a normative perception of needs, and the justification for every arm of the environment to be conducive in fashion to meet these wide varieties of needs (Shonibare \& Sheda, 2008). This is in line with the dictates of the National Policy on Education that "every Nigerian child shall have a right of equal educational opportunities irrespective of any real or imaginary disabilities" (FRN, 2004:3)

Low achievers are students whose academic performances are below expectation in spite of the fact that they may not have any known learning disability. Smith (2007) sees low achievers as students without disabilities whose academic performance is below that of their classmates. Brophy (1996) and Santrock (2004) have it that low achievers are known for inhibited classroom participation, low frustration thresh-hold, low self-esteem, adult dependency, attribution problems, easy discouragement, lack of interest or alienation to class activities and constant need of attention. Without intervention low-achievers do not exhibit high levels of achievement on academic measures (Woodward \& Brown, 2006). Many of them drop out of school as a result of inability to cope with the demands of learning tasks.

Failure in school results in stress and where the student lacks the skill to cope dropping out of school becomes almost inevitable. Education system these days sees social and emotional skills as part of core curriculum and must be integrated into school policy and practice (Huxley, Freeman \& Frydenberg, 2004). Coping skills problems are related to teachers having limited expertise in representing the ideas themselves (Allen \& Dlugokinski, 1992) and teachers have a vital role in promoting students coping skills (Huxley, Freeman \& Frydenberg, 2004). Allen \& Dlugokinski (1992) stated that coping skills instruction for children is only one piece of a more comprehensive intervention involving parents, teachers and other community supporters which can be utilized to improve the mental health and resiliency of children.

Coping is a 'complex and multidimensional process that is sensitive to both the environment and the personality of the individual' (Kilburn \& whitelock cited in edu palliative end- of-life care for oncology (nd:2). Coping is also defined as a response aimed at diminishing the physical, emotional and psychological burden that is linked to stressful life events and daily hassles (Synder,1999 cited in Tarik, llegan, Deniz \& Kutlu, 2008). To Tarik, llegan, Deniz and Kutlu (2008) it is understood to be adaptation activity that involves effort, and it is the element of effort which enables us to draw the distinction between coping and ready-made adaptation devices such as reflexes. Coping constitutes constantly changing cognitive, behavioural and emotional efforts to manage particular external and/or internal demands that are appraised as taxing or exceeding the resources of the individual (Lazarus \& Folkman, 1984 cited in Tarik, llegan, Deniz \& Kutlu (2008).Coping strategies therefore are strategies that individuals adopt in order to manage external and/internal challenges that exceed the resources of the individual. Though there are countless ways individuals cope with stressful situations, Passer and Smith (2007) noted that coping strategies can be grouped into three broad classes as problem focused coping strategies, emotion-focused strategies and seeking-social-support coping strategies. Problem-focused coping strategies attempt to confront and directly deal with the demands of the situation or to change the situation; emotion-focused coping strategies attempt to manage the emotional responses that emanate from stressful events and seeking-social-support coping strategies demand turning to others for assistance and emotional support in times of stress (Passer \& Smith). Frydenberg and Lewis (1999) in Boon (2009) proposed three coping strategies: solving the problem, reference to others, and non-productive coping. These strategies are similar to that of Passer and Smith (2007) except that non-productive coping strategies are merely wishful thinking, ignoring the problem and worrying and not just emotionfocused strategies. They usually predispose an individual who adopts them to more problems like greater anxiety, depression, etc. But Passer and Smith's emotion-focused coping strategies though usually palliative cannot in its absolute terms be said to be non-productive.

Learning difficulties put students at risk of leaving school (Firth, n.d) and coping profile of low-achievers include high use of non-productive coping strategies (Cheshire \& Cambell,1997 in Firth, n.d). Firth reported that Dweck and Sorich (1999) in their study discovered that many under-achievers have helpless orientation towards learning which is based on the belief that ability is a fixed entity, that there are few alternative strategies available and that appropriate response to failure is negative emotive rumination rather than active pursuit of alternative strategies. Based on the above, she suggested a programme of feedback from teachers that will encourage students to take on more of a mastery orientation in response to difficulty. Since the quality of teacher feedback is one such important external resource in relationship to coping responses by low achievers (Dweck, 2000 in Firth, n.d) and there appear to be consistent low completion rate at the UBE level (National Technical Working Group on Education, 2009), the study set out to investigate teachers' coping skill instruction for enhancing low achievers' coping skills to manage cognitive learning difficulties for sustainable universal basic education programme. The aim is to ascertain if low achievers are taught coping skills by their teachers with which to tackle task difficulties. The conservation of resources model of stress contributes valuable theoretical structure that ensures that the perspective on needs of low achievers is not only with the students' appraisal and coping skills, but also includes the responsibility of society to provide resources at a structure, rather than an 
individual level (Firth, nd). She went further to assert that these resources include professional development for teachers with regard to optimum teacher feedback. This teacher instruction on coping skill strategies seems not to have been ascertained. The following research questions and hypothesis guided the study:

a. What is the extent of teachers' instructions on problem-focused coping strategies to low-achievers in handling cognitive learning tasks difficulties?

b. What is the extent of teachers' instructions on emotion-focused coping strategies to low achievers in handling cognitive learning tasks difficulties?

c. What is the extent of teachers' instructions on seeking-social-support coping strategies of low-achievers in handling cognitive learning tasks difficulties?

$\mathrm{H}_{0}$ : There are no significant differences in the extent teachers instruct low-achievers on problem-focused, emotionfocused and seeking-social-support coping strategies in handling cognitive learning task difficulties.

\section{Method}

The study adopted a descriptive survey research design since the study intends to describe systematically events as they are. It was carried out in Awka South Local Government Area in Anambra State. There are eighteen state government owned secondary schools in the local government. The sample comprised 200 randomly sampled low achievers in JSS 11 in ten selected junior secondary schools. Seventy-five male low achievers and 125 female low achievers were sampled. These students were those who were considered by their teachers as performing below average when compared with their classmates. And the choice of this class of students was predicated upon the fact that they need appropriate coping strategies to survive the daunting tasks in secondary school.

The instrument used to collect the data was a researcher designed 20-item questionnaire tagged 'Teachers' Coping Skills Instruction for Enhancing Low Achievers' Coping Skills Questionnaire (TCSIELACSQ)'. It comprised two sections; section A sought to ascertain the bio-data of the respondents while section B consisted of 20 items used to answer the three research questions. It was structured using the 4-point scale of strongly agree, agree, disagree and strongly disagree. The instrument was validated by two experts in Educational Psychology and their suggestions were considered in drafting the final copy of the questionnaire. The questionnaire was administered with the help of classroom teachers who know the students that perform below average in their class. There was no time limit given but the instrument was collected as soon as the students were through with the filling in of the questionnaire. A total number of 187 copies of the questionnaire were returned representing 93.5\%. For male low achievers, $86.7 \%$ were returned while for female low achievers $99.2 \%$ were returned. The research questions were answered using mean scores and ANOVA was used to test the hypothesis.

\section{Results}

Table 1: Mean Rating of Male and Female Low Achievers' Responses on Teachers' Instruction on Direct Action Coping Strategies

\begin{tabular}{|c|c|c|c|c|}
\hline SN Items & Males & Decision & Females & Decision \\
\hline & $\overline{\mathbf{x}}$ & & $\overline{\mathbf{x}}$ & \\
\hline 1. When I find myself not coping with school work my teachers encourage me to make a plan for my work & 3.12 & Accepted & 3.59 & Accepted \\
\hline 2. My teachers tell me to set a goal I should achieve when I find myself not coping with my studies & 3.05 & Accepted & 3.28 & Accepted \\
\hline 3. My teachers tell me to work hard to achieve the goal I set & 3.11 & Accepted & 3.42 & Accepted \\
\hline 4. When I find myself not coping with my study my teachers encourage me to solve problems step by step & 3.12 & Accepted & 3.26 & Accepted \\
\hline $\begin{array}{l}\text { 5. When it looks as if I can't continue with my assignments my teachers encourage me to make sure I } \\
\text { attempt them }\end{array}$ & 3.24 & Accepted & 3.23 & ed \\
\hline $\begin{array}{l}\text { 6. When I find myself not being able to understand what I am studying my teachers tell me to continue } \\
\text { studying till I understand it. }\end{array}$ & 3.53 & Accepted & 3.48 & Accepted \\
\hline $\begin{array}{l}\text { 7. When I want to quit solving a problem my teachers tell me to think of many other ways I could use to } \\
\text { solve the problem. }\end{array}$ & 3.24 & Accepted & 3.40 & Accepted \\
\hline 8. Even when tasks seem difficult my teachers encourage me to make trails. & 3.24 & Acc & 3.26 & Acc \\
\hline 9. After solving a problem my teachers tell me to assess myself to know if I had achieved the goal I set. & $\begin{array}{l}3.15 \\
3.20\end{array}$ & Accepted & $\begin{array}{l}3.38 \\
3.37\end{array}$ & Accepted \\
\hline
\end{tabular}

From the table above, all the nine items on direct action coping strategies were accepted by both male and female lowachievers. Female students had higher mean scores on almost all the items except items 5 and 6 that have to do with persistency. On items which have to do with planning, setting of goals and divergent ways of tackling problems, female 
low-achievers to an extent agreed more that they are being instructed on these coping strategies. Male low-achievers had a grand mean of 3.20 while female low-achievers had 3.37 which is a strong indication that instructions were given on direct action coping strategy.

Table 2: Mean Rating of Male and Female Low Achievers' Responses on Teachers' Instruction on Emotion - Focused Coping Strategies

\begin{tabular}{lcccc}
\hline SN Items & Males Decision & Females Decision \\
& $\overline{\mathbf{x}}$ & $\overline{\mathbf{x}}$ & & \\
1. When I face a challenging situation my teachers tell me to tell myself that I can do it. & 3.95 Accepted & 3.63 & Accepted \\
2. My teachers tell me to first relax while facing a challenging situation & 2.77 Accepted & 2.58 & Accepted \\
3. When I face challenging tasks my teachers tell me to avoid thinking I can't handle the situation & 2.62 Accepted & 2.52 & Accepted \\
4. When facing challenging tasks my teachers tell me to breathe in and out to ease tension. & 2.81 Accepted & 2.93 & Accepted \\
5. My teachers tell me to forget about the problem and later come back to it when the tasks seem too & 2.41 Rejected & 2.39 & Rejected \\
challenging. & 2.84 Accepted & 2.84 & Accepted \\
6. My teachers tell me to see a challenging situation as a friendly one. & 2.90 & & 2.82 & \\
Grand Mean & & &
\end{tabular}

From the table above five out of six items enlisted in the emotion-focused coping strategies were accepted with the exception of item 5. Item 5 was rejected by both female and male low-achieving students. Also male low-achieving students agreed more that instruction was given on emotion-focused coping strategies to them than their female counterparts. The grand means of 2.90 for males and 2.82 for females show that instructions to a certain level were given on this kind of coping strategy to low achievers.

Table 3: Mean Rating of Male and Female Low Achievers' Responses on Teachers' Instruction on Seeking-SocialSupport Coping Strategies

\begin{tabular}{|c|c|c|c|c|}
\hline SN Items & $\begin{array}{c}\text { Males } \\
\mathrm{x}\end{array}$ & Decision & $\begin{array}{c}\text { Females } \\
\mathrm{X}\end{array}$ & s Decision \\
\hline 1. My teach & 3.29 & Ac & 3.36 & \\
\hline 2. Teac & 3.4 & & 3.25 & \\
\hline 3. Teachers tell me to ask more intelligent $p$ & 3.23 & Accepted & 3.40 & \\
\hline $\begin{array}{l}\text { When I find it difficult to cope with my school work my teachers tell me to study/read together with my } \\
\text { classmates. }\end{array}$ & 3.39 & Accepted & 3.39 & ccept \\
\hline $\begin{array}{l}\text { 5. My teachers tell me to tell my parents to help me in doing my assignments when they appear too } \\
\text { challenging to me. }\end{array}$ & 3.01 & Accepted & 2.98 & ep \\
\hline Grand Mean & 3.26 & & 3.28 & \\
\hline
\end{tabular}

The table above shows that all the items enlisted on seeking-social-support coping strategies were accepted by both male and female low achievers as instructed by their teachers. Grand means of 3.26 and 3.28 for males and females respectively show that low achievers were encouraged to seek help from their classmates and more intelligent ones when they feel that they are not coping with school challenges.

Table 4: ANOVA table on extent of teachers' coping skills instruction on the three classes of coping strategies

\begin{tabular}{lccccc}
\hline Source & Sum of squares & Df & Mean square & f- cal & Crit value \\
Between & 24.19 & 2 & 12.10 & & \\
Within (error) & 807.24 & 558 & 1.45 & 8.35 & 3.00 \\
Total & 831.43 & 560 & & & \\
\hline
\end{tabular}

Since the $\mathrm{f}$ - calculated (8.35) is greater than the critical value (3.00), we reject the null hypothesis that there is no significant difference in the extent of teachers' coping skills instruction on the three classes of the coping strategies. Therefore there is enough evidence to conclude that at least one mean is different from others.

\section{Scheffe Test}

To determine the direction of difference among the three mean, the Scheffe test was adopted. The F test values of the means are as follow: 
For $X_{1}$ versus $X_{2}=15.33$

For $\mathrm{X}_{2}$ versus $\mathrm{X}_{3}=14.17$

For $X_{1}$ versus $X_{3}=0.00000522$

Critical value for $\mathrm{F}^{1}=6$

Since the $f$ test values of $X_{1}$ versus $X_{2}$, and $X_{2}$ versus $X_{3}$ are greater than the critical value for $F^{1}, 6$, the significant differences are between $X_{1}$ versus $X_{2}$; and between $X_{2}$ and $X_{3}$. That is between direct action coping and emotion focused strategies; and between emotion-focused and seeking social support strategies.

\section{Discussion}

Research question one indicated that both female and male low-achievers agreed that they are instructed on direct action coping strategies by their teachers. Female students agreed more on direct action planning, setting of goals and divergent ways of tackling problems while male students agree more on teachers' instruction on resilience as means of coping with challenging learning situations. The grand mean showed that to a very great extent that low achievers are instructed on direct action coping strategies.

On emotion-focused coping strategies low achievers agreed to 5 out of the six items. The rejection of item 5 by both female and male low-achievers suggests that teachers do not lay much emphasis on such palliative measure which may encourage procrastination on the part of the learners. However male low achievers seem to agree more than the female low achievers that teachers instruct them on emotion-focused coping strategies. The grand mean also shows that teachers to an extent instruct low achievers on emotion-focused coping strategies in order to cope with challenging cognitive tasks. The third research question investigated the extent of instruction on seeking-social support coping strategies. From the analysis, both female and male low achievers agreed that they are instructed on this strategy. Students, in other words, were encouraged by their teachers to go beyond themselves and seek the support of others who can be of help to them. Instructions on these coping strategies indicate that teachers are responding to the call for schools to become more active in students' emotional education (Huxley, Freeman \& Frydenberg, 2004).

Testing the null hypothesis that there would not be a non-chanced difference on the extent of instruction on the three classes of coping strategies, it was found using ANOVA that there is a significant difference on the extent of teachers' coping skills instruction. To ascertain the direction of difference, the data was subjected to further analysis using Scheffe test and the statistical difference lay on direct action coping strategies and emotion-focused strategies; and also on emotion-focused coping strategies and seeking social support coping strategies. There was no significant difference in the direction of action coping strategies and seeking social support coping strategies. What this implies is that teachers instruct more on the other two strategies than the emotion-focused strategies and this further indicates teachers' competency in instructing students on coping strategies. They understand that problem focused coping methods and seeking social support are most associated with favourable adjustment to stressors (Tarik, llgen, Deniz, \& KUTLU, 2008; Passer \& Smith, 2007). Emotion focused coping strategies are palliative in nature and may be dangerous when they degenerate into wishful thinking, self blame, etc.

\section{Conclusion}

The study found out that to a very great extent that instructions on coping strategies are given to low achievers and problem-focused and seeking-social-support coping strategies were given more attention than emotion-focused coping strategies. This implies that teachers implicitly were knowledgeable about the weight that may be given to each strategy based on evidence from other studies, but there appears to be continuous drop-out from school and an abysmal completion rate in the UBE programme. It then calls the attention of stakeholders to find out ways of making sure that low-achievers utilize the knowledge they have gained from their teachers. The instruction is not just for knowledge sake but must be practiced in real life situations. There is no doubt that this class of students may even after receiving instructions on these productive skills prefer easy going (non-productive) coping skills. Efforts must be made to get low achievers realize that these are life surviving skills which will help them cope with their academic studies for the laudable UBE programme to be sustained.

\section{Recommendations}

Based on the findings the following are recommended: 
A. Frantic efforts should be made by educational planners and administrators to develop a programme that will enable low achievers in the UBE programme to practice the coping skills in context.

B. There should be professional training for teachers on the use of available psychological tools to encourage low achievers to utilize productive coping skills.

C. Since teachers have been found to instruct low achievers on coping strategies, they should be encouraged to step up their actions in this direction.

\section{References}

Allen, S. F., Dlugokinski, E. L. (1992). Teaching Children Emotional Competence Skills in the Classroom. Paper presented at the Annual Convention of the American Psychological Association (100th, Washington, DC, August 14-18, 1992).

Boon,H. J. (2009).Coping with School Moves. ocs.sfu.ca/aare/index.php/AARE_2009/aare_2009/paper/.../1031

Edu in Palliative and End-of-Life care for oncology (nd). Cultural considerations when caring

For African Americans. Plenary- AA: Cancer and the African Experience. www.cancer.gov/.../epeco/cancer -african-americanexperience.

Federal Republic of Nigeria. (2000). National Policy on Education. Lagos: FGN Press.

Federal Republic of Nigeria. (2004). National Policy on Education. Lagos: FGN Press.

Federal Republic of Nigeria. (2009). Report of the Vision 2020 National technical Working Group on Education sector.

Firth, N. (n.d). The role of perceived control in effective coping: Intervention programmes for students with learning difficulties. PostScript, volume 4 (1), 34 - 48. www. Edfac.melbourne.edu/research/resources/.../vol14_1_firthpdf

Huxley, L. , Freeman, E. \& Frydenberg, E. (2004). Teaching coping skills: Implications for practice. A paper presented at AARE Conference Melbourne, Australia, December, 2004.

Ogunleye, A. \& Udeani, U. (2010). Enhancing quality assurance in the UBE scheme in Nigeria through teachers' effectiveness and an elearning environment. Proceedings of the $24^{\text {th }}$ congress of the Nigeria Academy of Education held at the NCCE conference room, Abuja 2-6 November, 2009.

Okoro, D. U. (2010). Universal Basic Education Programmes: Policy achievement and challenges. Proceedings of the $24^{\text {th }}$ congress of the Nigeria Academy of Education held at the NCCE conference room, Abuja, 2-6 November, 2009.

Passer, M. W. \& Smith, R. E. (2007). Psychology: The science of mind and behaviour. New York: McGraw-Hill Companies.

Santrock, J. W. (2004). Educational Psychology (2nd ed). New York: McGraw-Hill Companies.

Shonibare, D. O. \& Sheda, N. E. D. C. (2008). A contextual model for inclusive education. Proceedings of the $23^{\text {rd }}$ annual congress of the Nigerian Academy of Education on Access, quality and cost in Nigerian education held at the University of Nigeria, Nsukka $4^{\text {th }}-6^{\text {th }}$ Novermber, 2008 .

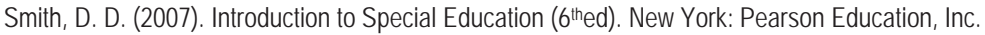

Tarik, T., Ilgen, M, Deniz, E. G. \& Kutlum, K. (2008). Relationship between anxiety, coping Strategies and characteristics of patients with diabetics. http://www.lglo.com/content/6/1/79

Woodward, J. R. \& Brown, C. (2006). Meeting the curricular needs of academically low achieving students in middle grade mathematics. The Journal of Special Education, 40 (3)151-159. 